\title{
MICROSTRUCTURE AND MECHANICAL BEHAVIOR OF SIMILAR AND DISSIMILAR AA2024 AND AA7039 FRICTION STIR WELDS
}

\author{
Chaitanya Sharma $^{1 *}$ - Vikas Upadhyay ${ }^{2}$ \\ ${ }^{1}$ Department of Mechanical Engineering, Rustamji Institute of Technology, BSF Academy, Gwalior, India-475005 \\ ${ }^{2}$ Department of Mechanical Engineering, National Institute of Technology Patna, India-800005
}

\begin{tabular}{l}
\hline ARTICLE INFO \\
\hline Article history: \\
Received: 14.10 .2019$. \\
Received in revised form: 23.01 .2020$. \\
Accepted: 25.1 .2020$. \\
\hline Keywords: \\
Friction stir welding \\
Dissimilar aluminum alloys \\
Characterization \\
Fracture locations \\
Fractography \\
SEM \\
\hline DOI: https://doi.org/10.30765/er.1533 \\
\hline
\end{tabular}

\begin{abstract}
:
In this work, similar and dissimilar friction stir welds of AA2024 and AA7039 were formed using optimized process parameters and truncated threaded tool. Characterization of weld joints for mechanical and microstructural properties was performed by tensile test, micro hardness test, optical microscopy, scanning electron microscopy, and energy dispersive spectrometry. The tensile strength of similar joints was higher than dissimilar joints despite lower microhardness of former. Fracture of FSW joints was found to be started by the fracture of strengthening precipitate $\theta$ or $\eta$ or both in the region of tensile fracture. Dissimilar joints and similar joints of AA7039 exhibited ductile fracture mode while similar joints of AA2024 showed brittle fracture mode.
\end{abstract}

\section{Introduction}

Aluminum alloys are extensively used for various industrial applications ranging from aerospace to sporting goods because of excellent strength to weight ratio and exceptional corrosion resistance. Alloys of $2 \mathrm{xxx}$ and $7 \mathrm{xxx}$ series are aerospace grade heat treatable alloys and are widely used in aircraft fittings, missile parts, worm gears and structural components, to name a few [1,2]. In many applications, joining of these alloys in similar and dissimilar condition is required to meet out the specific requirements. Welding of similar aluminum alloys by liquid state, fusion welding processes is itself a challenge due to their high thermal conductivity, whereas welding of dissimilar aluminum alloys is comparatively more complex because of difference in melting temperature and thermal conductivity of the base metals [3]. Friction stir welding (FSW) is a solid state joining process, extensively used in recent past for welding of similar aluminum alloys as melting and recasting of base alloys is not involved in this process and as a result most of the problems associated with fusion welding were eliminated at its own. In addition to this, FSW is also an environment friendly process and can be used for dissimilar welding of heat treatable and non-heat treatable aluminum alloys $[4,5]$. However, FSW of dissimilar alloys/materials require careful selection of various process parameters such as tool shift, shoulder diameter $(D)$, pin diameter $(d)$, shoulder to pin diameter $(D / d)$ ratio, rotary speed, welding speed, etc. along with plates' location to ensure optimal heat input for efficient material flow and proper mixing of the base materials [6-12].

The research reported in literature related to $2 \mathrm{xxx}$ and $7 \mathrm{xxx}$ series alloys has been reviewed and the main outcomes of the research work are presented below. Cavaliere et al. [2] performed dissimilar FSW of AA7075 and AA2024 alloys, parallel and perpendicular to rolling direction of base metals. They observed higher hardness than base metals in nugget zone and HAZ, and no recrystallization in TMAZ. Increase in welding speed during FSW of AA2024-AA7075 alloy leads to kissing bond and pores formation especially with AA2024 placed on retreating side. No effect of welding speed was observed on the heterogeneous distribution of alloying elements in the stir zone [6]. Silva et al. [7] placed AA7075 alloy on retreating side and varied rotation speed in the steps of 400, 1000, $2000 \mathrm{rpm}$ while keeping welding speed fixed at $254 \mathrm{~mm} / \mathrm{min}$. Varying degree of mixing was witnessed with variation in rotation speed i.e. limited mixing at low rotation speed and

\footnotetext{
* Corresponding author.

E-mail address: chaitanya.sharmaji@gmail.com
} 
onion ring like intense mixing at high speed. Increase in welding speed at constant rotary speed resulted in significant decrease in nugget zone grain size of similar joints of AA7075 and AA5083 while no obvious effect was observed for dissimilar joints of AA7075-AA5083 where two different base metals conceal the grain refining due to increasing welding speed [8]. The increase in rotary speed resulted in the widening of TMAZ, higher degree of mixing, grain coarsening and decreases in the nugget zone hardness of similar and dissimilar joints of AA7075 and AA2024 [9]. Greater tendency for the formation of tunnel and kissing bond defects were observed at higher rotary and traverse speeds. The use of longer pins can avoid formation of these defects at higher traverse speed. Minimum pin diameter should be equal to plate thickness to avoid lack of penetration defect [10]. The tool offset up to $1 \mathrm{~mm}$ towards the advancing side enhanced mechanical properties of AA2024-AA7075 dissimilar welds [11]. The D/d ratio affected weld mechanical properties of AA2014AA7075 joints and maximum tensile strength occurred at a ratio of 3. Joint hardness value was also slightly higher than AA2014 base metal because of proper mixing of material in stir zone [12].

Sometimes, welding of plates with thickness ratio greater than one is required as in case of tailor-made blanks. This again requires a very careful selection of welding parameters as increase in thickness ratio generally have an adverse effect on weld mechanical properties. Microstructural features and mechanical properties of dissimilar alloy, dissimilar thickness welded joints were ominously different from same alloy, same thickness welded joints. Also, mechanical properties of the dissimilar welds decrease with increase in thickness ratio of joining plates [13]. The thickness ratio greater than unity had adverse effect on the weld strength and at thickness ratio of 1.3, tensile strength of dissimilar joints was less than that of unwelded base metals [14].

The properties of dissimilar defect free welds are obtained by considering mechanical properties of low strength base material. Grain size is also not the dominating factor to determine the microhardness in dissimilar welds of precipitation hardening alloys [15]. Grain size was much finer on advancing side (AA2219) than retreating side and hardness profile in stir zone was inhomogeneous due to inadequate mixing of AA2219 and AA7039 [16]. A mixed structure containing both base metals with heterogeneous distribution of alloying element $(\mathrm{Cu}$ and $\mathrm{Zn})$ in weld region were observed in AA2024-AA7039 joints. Dissolution dominated over reprecipitation and resulted in softening. The strength efficiency of weld joints was higher than elongation efficiency [17]. High tensile strength was achieved for dissimilar welds AA2219-AA7475 which was comparable to that of similar joints tensile strength efficiency [18].

It is evident from the literature review that very less literature was reported on dissimilar welding of AA2024 and AA7039 alloys. In this work, an effort has been made to carry out a comprehensive study of mechanical properties and microstructure of dissimilar welding of AA2024 and AA7039 alloys and to simultaneously study, compare and contrast them with the mechanical and microstructural properties of similar welds of both the base metals to get better understanding of underlying phenomena.

\section{Material and experimental procedures}

The weight percentage of principal constituents and mechanical properties of the base metals (AA 2024 and AA 7039) are presented in Table 1 and 2 respectively. The ultimate tensile strength and hardness of AA2024 is higher than AA7039.

Table 1. Chemical composition of base metals.

\begin{tabular}{|c|c|c|c|c|c|c|}
\hline \multirow{2}{*}{ Alloy } & \multicolumn{5}{|c|}{ Chemical Composition (Wt. \%) } \\
\cline { 2 - 7 } & $\mathbf{M g}$ & $\mathbf{M n}$ & $\mathbf{C u}$ & $\mathbf{Z n}$ & $\mathbf{S i}$ & $\mathbf{F e}$ \\
\hline $\mathbf{2 0 2 4}$ & 2.56 & 0.34 & 3.83 & - & 0.13 & 0.55 \\
\hline $\mathbf{7 0 3 9}$ & 2.37 & 0.68 & .05 & 4.69 & 0.31 & 0.69 \\
\hline
\end{tabular}


Table 2. Mechanical properties of base metals.

\begin{tabular}{|c|c|c|c|c|}
\hline \multirow{2}{*}{ Alloy } & \multicolumn{4}{|c|}{ Mechanical Properties } \\
\cline { 2 - 5 } & $\begin{array}{c}\text { Yield } \\
\text { strength } \\
(\mathbf{M P a})\end{array}$ & $\begin{array}{c}\text { Ultimate } \\
\text { tensile } \\
\text { strength (MPa) }\end{array}$ & $\begin{array}{c}\text { Elongation } \\
(\mathbf{\%})\end{array}$ & $\begin{array}{c}\text { Micro- } \\
\text { hardness } \\
(\mathbf{H v})\end{array}$ \\
\hline $\mathbf{2 0 2 4}$ & 320.7 & 456.6 & 19.4 & 154.3 \\
\hline $\mathbf{7 0 3 9}$ & 328.0 & 414 & 15.1 & 135 \\
\hline
\end{tabular}

In this work, $5 \mathrm{~mm}$ thick plates of AA 2024 (rolled) and AA 7039 (extruded) in T6 temper state were cut down to size of $50 \mathrm{~mm} \times 300 \mathrm{~mm}$ and their abutting surfaces were machined to ensure metal to metal contact in butt joint configuration during welding. AA 7039 was kept on advancing side and AA 2024 was kept on retreating side during FSW. A flat shoulder and threaded taper pin tool was held in modified milling machine (HMT India) and imparted a rotary speed of $635 \mathrm{rpm}$ and traverse speed of $75 \mathrm{~mm} \mathrm{~min}^{-1}$. All the welds were formed at this combination only as it was found as the best combination in pilot experiments.

Standard grinding and polishing practice was used to prepare sample for microstructural characterization and Kellers's reagent was used to etch all the weld samples either similar or dissimilar. Microstructural characterization of weld joints was performed by optical microscope (Leica, Germany) and FE-SEM (Zeiss Ultra Plus, Germany). Mechanical characterization of weld joints was performed by tensile and micro hardness tests. Flat tensile specimens were made as per ASTM E8M-04 standard and tested at a strain rate of $1 \mathrm{~mm} \mathrm{~min}^{-}$ 1. Micro-hardness variation across the FSW joints was determined by Vickers micro-hardness tester (VHM$002 \mathrm{~V}$ Walter UHL, Germany) at a load of $1 \mathrm{~N}$ and dwell time of 30 seconds. The detailed experimental procedure was reported elsewhere [17].

\section{Results}

\subsection{Microstructure}

The microstructure of similar FSW joints and both the base metals are presented in figure 1 and that of dissimilar FSW joints is presented in figure 2. The alloy AA2024 displayed pancake microstructure i.e. elongated grains and intermetallic/strengthening particles aligned along the rolling direction. The length and width of grains were $120.1 \mu \mathrm{m}$ and $18.2 \mu \mathrm{m}$ respectively for base metal AA2024. The base metal AA7039 had equiaxed grain of size $44.3 \mu \mathrm{m}$ and randomly distributed intermetallic/strengthening particles. It is well known that during FSW, base metals experiences extreme thermal and mechanical stresses which transform base metal microstructure and results in the creation of stir zone and HAZ. The similar and dissimilar FSW joints exhibited well defined trapezoidal stir zone and HAZ, surrounded by unaffected base metal(s) (Figure 1 a \& b, Figure 2 a) [4]. Stir zone lies just below the tool shoulder. In this region, rotating and traversing tool deforms and transports the metal and forms stir zone which can be divided into WNZ and TMAZ. The similar and dissimilar FSW joints displayed varying microstructural features in WNZ, TMAZ and HAZ. WNZ experiences greatest thermal and mechanical stresses owing to severe plastic deformation and friction at tool-metal interface. The thermal and mechanical stresses are great enough to overcome stacking fault energy to initiate dynamic recrystallization. Therefore, all the WNZs showed dynamically recrystallized grains (Figure $1 \mathrm{c} \& \mathrm{~d}$, Figure 2 a-d). The $\alpha$ aluminum grain size in WNZ of similar FSW joints of AA2024, AA7039 and dissimilar FSW joints of AA2024 and AA7039 were $6.6 \mu \mathrm{m} 13.12 \mu \mathrm{m}$ and $7.1 \mu \mathrm{m}$ respectively. WNZ is surrounded by TMAZ which is the separation boundary between WNZ and HAZ. TMAZ showed deformed unrecrystallized grains whose width was smaller than the undeformed grains while length was greater than the undeformed grains. Deformed grains width in TMAZs of similar joints of AA2024 and AA7039 FSW joints were $8.6 \mu \mathrm{m}$, and $37.3 \mu \mathrm{m}$ respectively. In case of dissimilar FSW joint, the width of deformed grains on AS and RS were $8.6 \mu \mathrm{m}$, and $37.3 \mu \mathrm{m}$, respectively. 

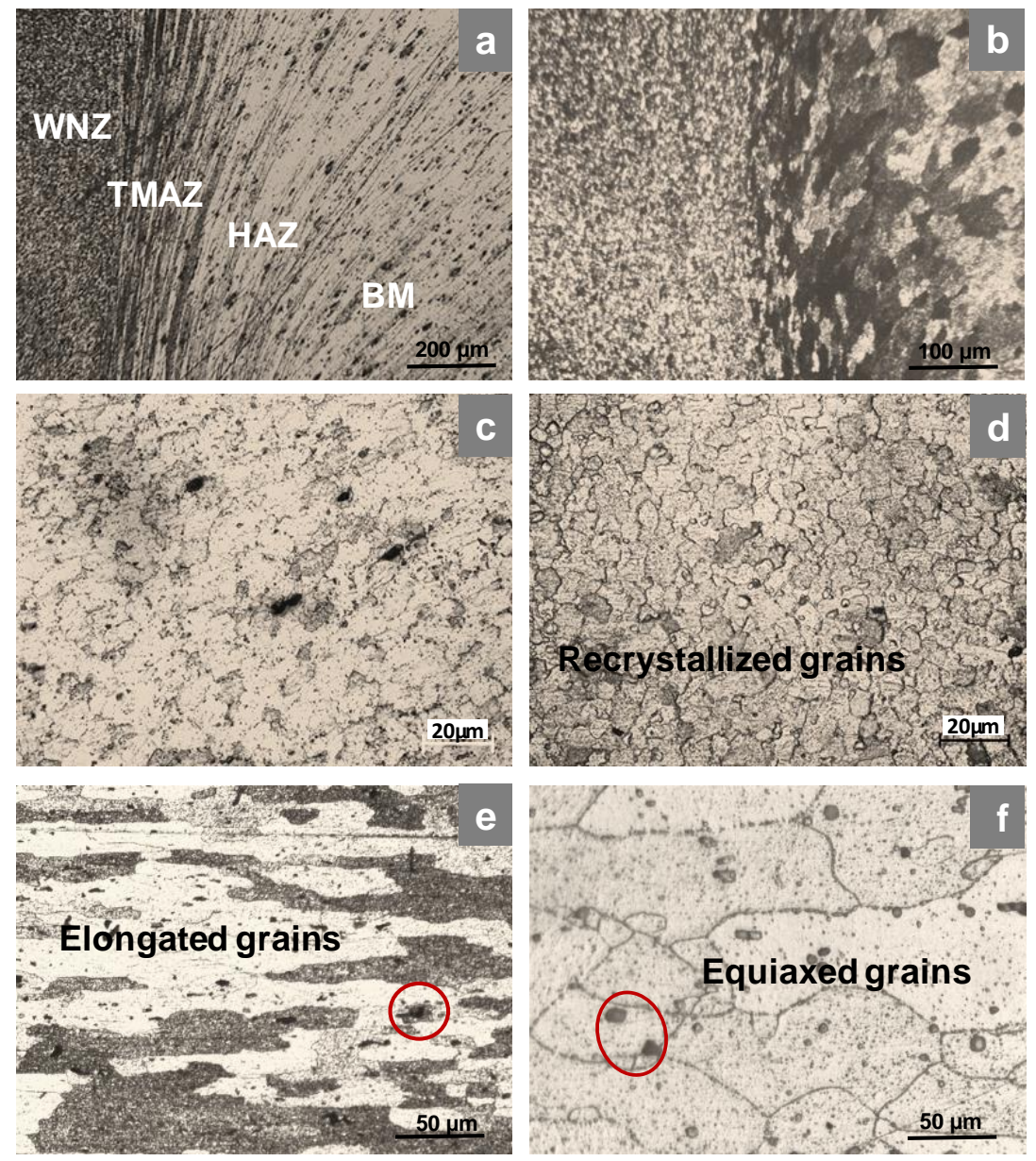

Figure 1. Microstructure evolution in similar FSW joints; (a), (b) different zones, (c) and (d) WNZ in AA2024 and AA7039 (e) base metal AA2024 (f) base metal AA7039.

As the TMAZ lies at the outer region of stir zone, the available thermal and mechanical stresses are somewhat smaller and couldn't initiate the recrystallization in this narrow region adjacent to WNZ. Hence, TMAZs of similar and dissimilar FSW joints showed deformed and unrecrystallized grains [19, 20]. The rotating tool shoulder drags the base metal in this region resulting in reduced width and increased length of bent deformed grains. HAZ is a region adjacent to TMAZ, where base metal experiences thermal excursion due to conduction of heat from central stir zone. HAZ of similar and dissimilar FSW joints showed microstructure similar to base metals except significant coarsening of the grains. The size of grains in HAZs of AA2024 and AA7039 similar FSW joints were $43.1 \mu \mathrm{m}$, and $75.7 \mu \mathrm{m}$ respectively. While, in case of dissimilar FSW joint, the size of coarsened grains on AS and RS were $28.3 \mu \mathrm{m}$, and $37.3 \mu \mathrm{m}$, respectively.

Weld microstructure was a mix structure of both the base metals (Figure $2 \mathrm{~b} \& \mathrm{c}$ ) and exhibited features formed due to solid state asymmetric flow and mixing of both the base metals. This can be easily confirmed from the composition of weld metal in the WNZ of dissimilar FSW joint which presented abrupt decrease in the weight $\%$ of constituent elements. The composition of weld metal as determined by EDS comprises of $\mathrm{Cu}$ $1.86 \%, \mathrm{Mg} 1.57 \%, \mathrm{Zn} 2.51 \%$, Mn $0.38 \%$, Al 93.61\%.

Further, regions comprising AA2024 (dark) and AA7039 (bright) are easily identified by the change in contrast followed by transition in the alloy composition/constituents particles which can be attributed to mechanical mixing. Mechanical mixing of base metals AA2024 and AA7039 in WNZ of dissimilar welded joints resulted in the formation of regions comprising either AA2024 or AA7039 in majority, thus making them rich either in $\mathrm{Zn}$ or $\mathrm{Cu}[6,17]$. 


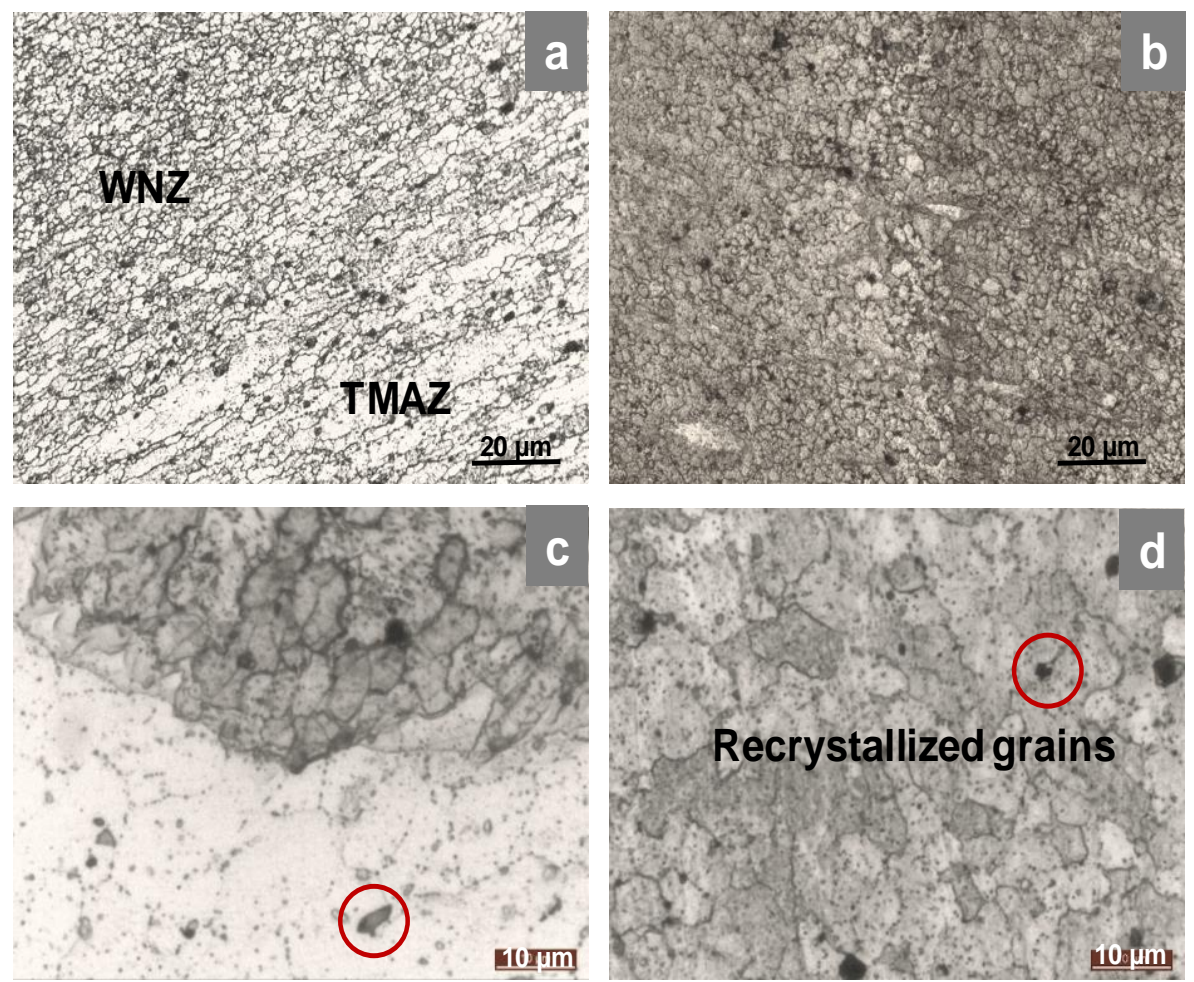

Figure 2. Microstructure evolution in dissimilar FSW joints (a) Different zones, (b) WNZ showing the mixing of base metals, (c) High magnification micrograph showing distinct region of base metals AA2024 and AA7039 in stir zone and, (d) Region of exhibiting heterogeneous mixing in stir zone.

Weight $\%$ of $\mathrm{Zn}$ increased from RS to AS and reverse trend was observed for $\mathrm{Cu}$ as confirmed from elemental mapping shown in Figure 3. The elemental mapping confirmed the variation of the major constituent elements present in the WNZ of dissimilar FSW joints due to mechanical mixing. Elemental mapping revealed the presence of $\mathrm{Fe}$ in the stir zone (Figure 3e) which may be attributed either to its presence in base metal or its inclusion from tool wear occurred during solid state plastic deformation in FSW.

Figure 4 shows the composition of strengthening particles obtained by EDS. Based on the composition $\theta$ $\left(\mathrm{Al}_{2} \mathrm{Cu}\right)$ and $\eta\left(\mathrm{ZnMg}_{2}\right)$ strengthening precipitates were observed in the WNZ of dissimilar weld joints. Similar and dissimilar joints were developed using FSW and believed to have undergone similar kind of thermal and mechanical deformation as both were developed using similar process parameters. However, similar and dissimilar FSW joints have demonstrated different microstructural features despite the fact that both joints type had identical trapezoidal stir zone surrounded by HAZ on both sides. The difference are summarized as follows: The dissimilar joints showed different lamellae as shown in figure 5 resulting in bright and dark regions rich in $\mathrm{Zn}$ or $\mathrm{Cu}$, while no such feature was observed in case of similar joints. Solid state complex material flow of two different base metals is responsible for the formation of lamellae comprising bright and dark regions. Further, diffusion seems to be incomplete and resulted in the varying composition on account of heterogeneous microstructure of stir zone of dissimilar joints. During FSW, tool shoulder transport AA7039 from front of AS to back of RS. This flow of material along with incomplete diffusion can be held responsible for the variation of $\mathrm{Zn}$ and $\mathrm{Cu}$ from As to RS [6, 17]. Because of this, dissimilar joints were more heterogeneous than similar joints in which only one material flows for the formation of weld in solid state. At last, dissimilar joints exhibited $\theta$ and $\eta$ type precipitates in stir zone due to mixing of both the base metals as compared to similar weld which exhibited either $\theta$ or $\eta$ type precipitates only. 

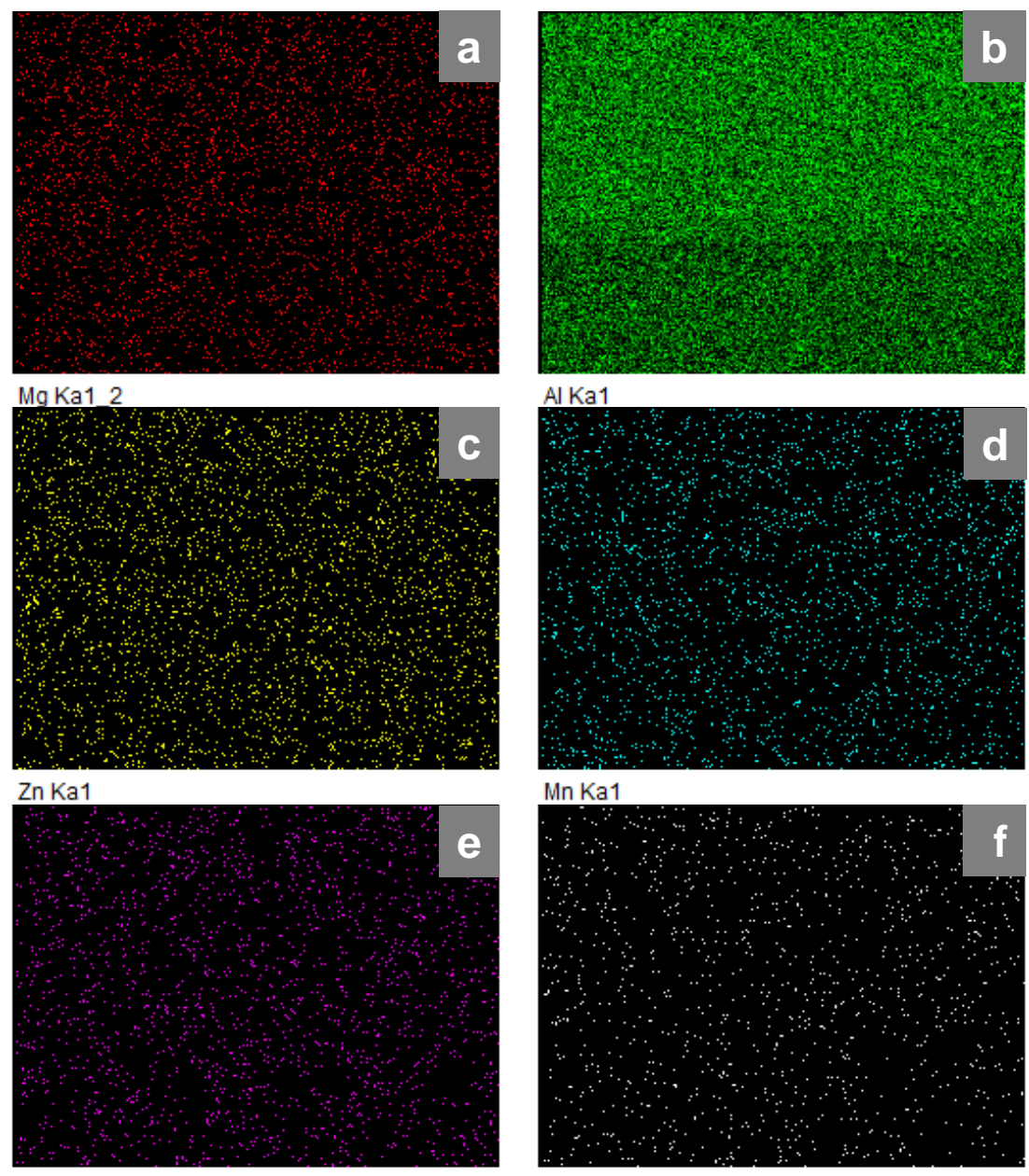

Fe Ka1

Cu Ka1

Figure 3. EDS elemental mapping showing the variation of constituent elements in WNZ of dissimilar FSW joints.
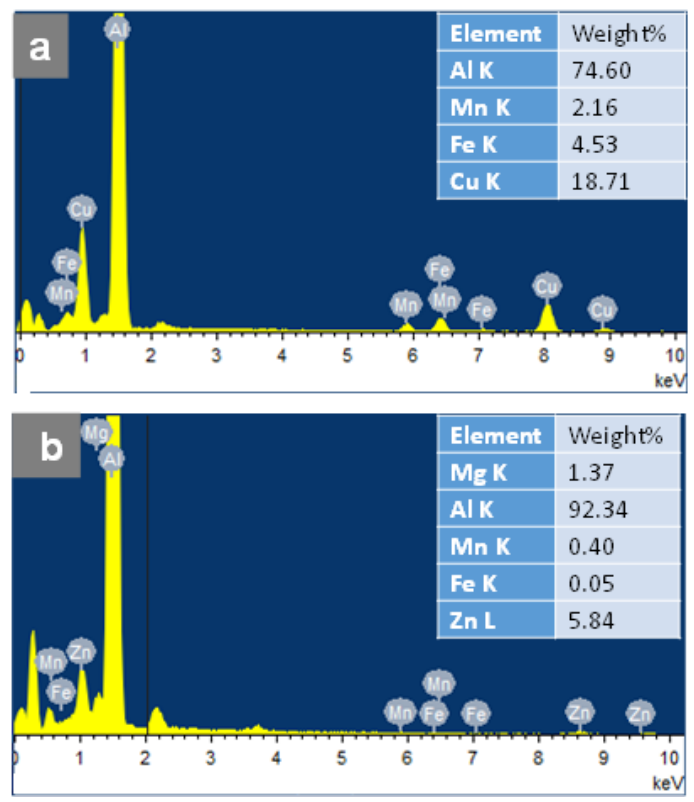

Figure 4. EDS results showing the composition of constituent particles (a) $\mathrm{Cu}$ rich $\theta$ particles and, (b) $\mathrm{Zn}$ rich $\eta$ particles. 


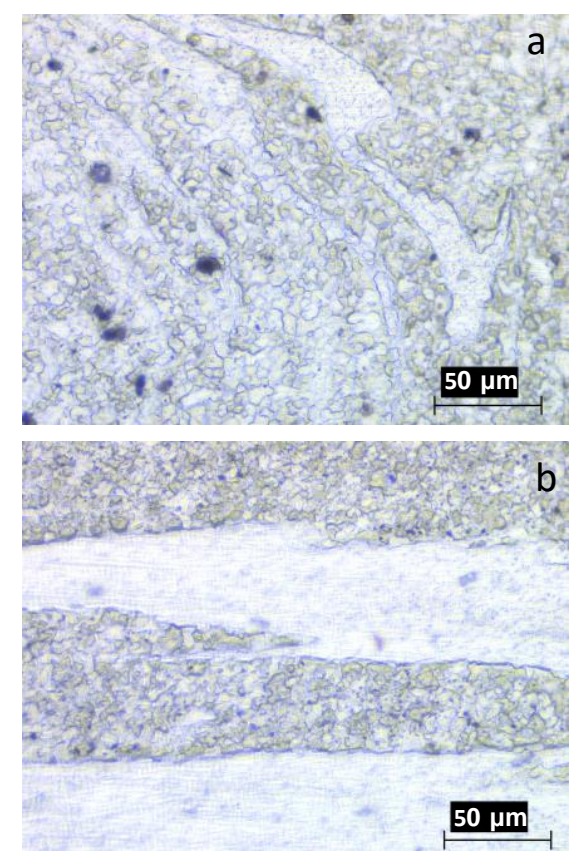

Figure 5. Lamellae microstructure in dissimilar FSW joint of AA2024-AA7039.

\subsection{Mechanical properties}

\subsubsection{Microhardness}

Friction stir welding influences the microstructure and may form one or other kind of welding defects therefore has great impact on mechanical properties of the weld joints. Microhardness measurements were carried out at mid thickness in transverse direction to study effect of FSW on microstructure, and microhardness of similar and dissimilar welds. Figure 6 shows the variation of microhardness across the traverse plane of developed similar and dissimilar weld joints after FSW. Microhardness of base metals was also determined to clearly visualize the impact of FSW. The average microhardness of base metal AA2024 and AA7039 was $153 \mathrm{Hv}$ and $135 \mathrm{Hv}$ respectively. The average microhardness in weld nugget zone was 137.3 $\mathrm{Hv}$ and $115.3 \mathrm{Hv}$ for similar weld of AA2024 and AA7039 respectively and that of dissimilar weld was 162.6 Hv. Thus, the average microhardness in the weld nugget of similar welds was lower than the respective base metal and opposite trend was witnessed for dissimilar weld. The average microhardness in HAZ of similar weld joints of AA2024 and AA7039 was $109.2 \mathrm{Hv}$ and $103 \mathrm{Hv}$ while in HAZ of dissimilar weld was 155.2 Hv. Hardness maxima appeared at center in WNZ in case of dissimilar weld while for similar weld it was located at the TMAZ. No effect was observed on the location of hardness minima which appeared in the HAZ for all welds. Also, softened zones were found in both sides HAZ.

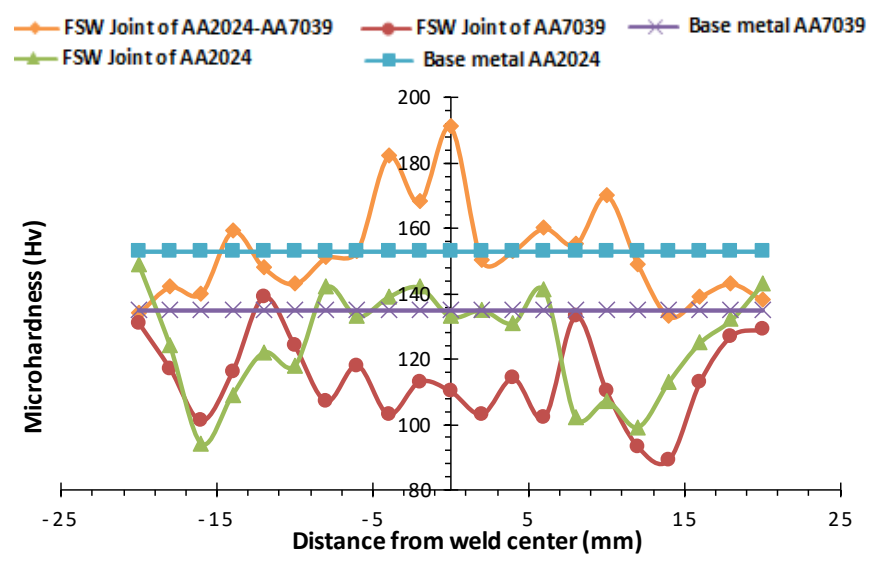

Figure 6. Microhardness variation for similar and dissimilar FSW joints. 
The trend of variation of hardness in HAZ was similar to that in WNZ of similar and dissimilar welds. The average microhardness in the WNZs and HAZs of similar welds was lower than respective base metal and same was found to be higher for dissimilar welds. In comparison of similar welds, the dissimilar welds exhibited higher microhardness in WNZ and HAZ. Results similar to this research were also reported for dissimilar joints of AA7075-AA5083 and AA2024-AA7075 which presented higher hardness in nugget zone and HAZ than low strength base metal $[2,8]$.

In line with general expectation, type of welding i.e. similar or dissimilar were found to have paramount influence on microhardness profile of welds. Similar welds of both AA2024 and AA7039 exhibited softened region comprising weld nugget and HAZs while dissimilar weld showed an opposite behavior. These results indirectly confirmed the findings of the microstructure investigation and tensile properties of weld joints as compared to base metals. Microhardness results are in good agreement with microstructural observations. The variation of microhardness in weld region may be due to the difference in microstructure of weld material and base metals. Aluminum matrix is softer than strengthening precipitates and the refinement of strengthening precipitates is believed to have more profound influence on the microhardness evolution in comparison to refinement of aluminum matrix. During FSW, WNZ is solutionized, quenched and formed super saturated solid solution owing to thermal cycle. The resulting weld is in unstable state which after FSW ages naturally at room temperature. The fine $\left(\eta^{\prime}\right.$ or $\left.\theta^{\prime}\right)$ precipitates dissolves easily in the matrix and increases solute concentration in super saturated solid solution. The post weld natural aging results in homogeneous precipitation of finer strengthening precipitate which improves hardness in WNZ [20,21]. The dominance of dissolution over precipitation is supposed to be responsible for reduced microhardness of WNZ than base metals in case of similar weld joints. The coarsening of preexisting precipitates is responsible for the lowering of the microhardness in the HAZ of similar weld joints [4]. The increased microhardness of dissimilar welds after FSW may be owed to the presence of complex intercalation patterns which alter the microstructural spacing and structure. These changes in microstructure were accounted for microhardness variations. In addition to this, post weld ageing was believed to be more effective in case of dissimilar weld joints than similar joints and greatly contribute to improve microhardness owing to reprecipitation of strengthening precipitates from saturated base material matrix.

\subsubsection{Tensile properties}

Tensile tests were performed by applying uniaxial tensile load on the specimens and strain-stress curve were plotted with the help of load and deformation data thus obtained. The strain-stress curves for similar and dissimilar weld joints and base metals are presented in Figure 7.

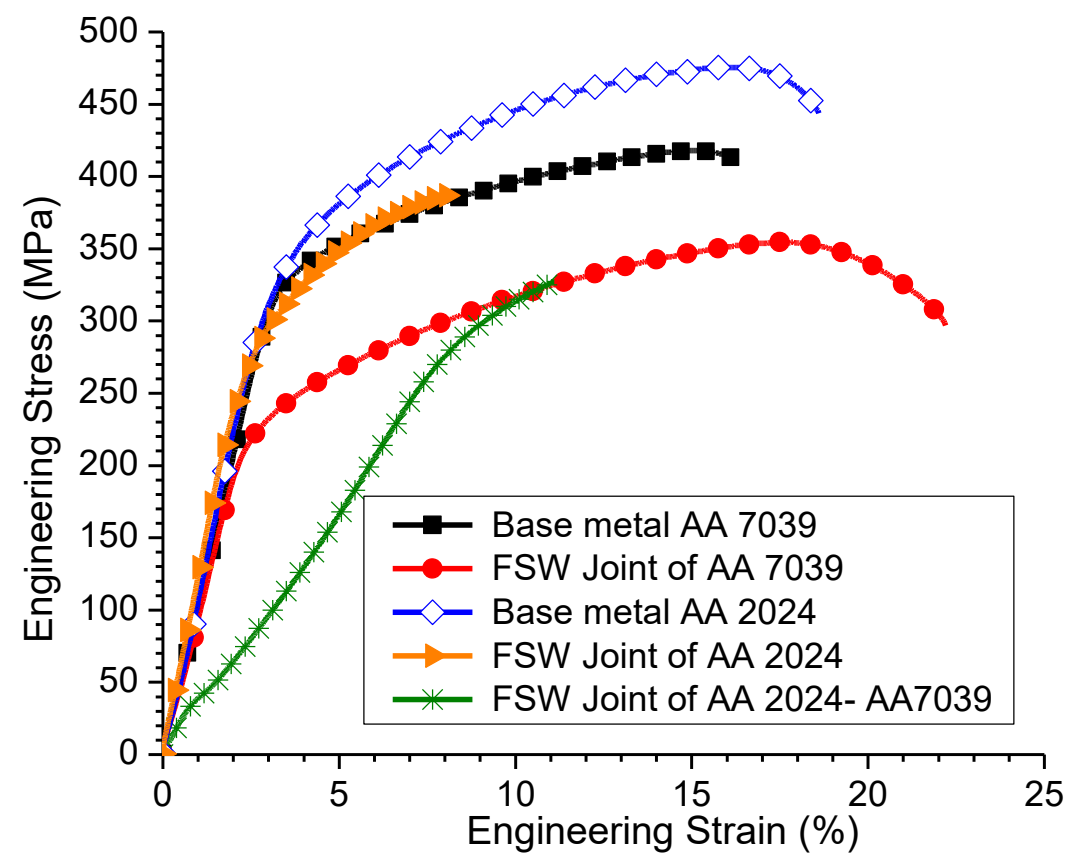

Figure 7. Engineering strain-stress curve for similar and dissimilar FSW joints. 
The careful examination of stress-strain curves revealed that shape and area under the curves is distinctly different for similar and dissimilar weld joints as well as for both the base metals therefore, each exhibited mechanical properties different than other. Tensile properties of similar and dissimilar weld joints were poorer to respective base metal(s) as evident from the stress-strain curves except the ductility of AA7039 weld joints. Tensile properties of similar welded joints namely, ultimate tensile strength (UTS), yield strength (YS) and \% elongation at fracture (\% EL) were $377.7 \mathrm{MPa}, 260.1 \mathrm{MPa}$, and $7.82 \%$ and $354.4 \mathrm{MPa}, 217.3 \mathrm{MPa}$, and $21.4 \%$ for AA2024 and AA7039 similar weld joints, respectively. Similarly, UTS, YS, and \% EL were 456.6 MPa, $320.7 \mathrm{MPa}, 19.3 \%$ and $414 \mathrm{MPa}, 328 \mathrm{MPa}, 15.1 \%$ for base metal AA2024 and AA7039, respectively. The UTS, YS, and \% EL for dissimilar welded joints were obtained as $327 \mathrm{MPa}, 48.2 \mathrm{MPa}$ and $11.1 \%$, respectively. Though, tensile strength of dissimilar welded joints was slightly smaller than both the similar weld joints but difference was insignificant. The yield strength was found substantially smaller than both the similar weld joints. Percentage elongation of dissimilar weld joints was greater compared to AA2024 similar weld joints whereas opposite trend was obtained for AA7039 similar weld joint. Elasticity modulus of dissimilar weld joint appears to be smaller than both the similar weld joints and base metals as the slope of linear portion of the strain-stress curve was found to be considerably less steep than the similar weld joints and base metals. Similarly, low value of modulus of elasticity was observed for dissimilar joints of AA2024-AA7075 than base metals by Cavaliere et al. [2].

The joint efficiency is defined as the ratio of weld joint property to that of base metal. The properties of AA7039 was used to determine the different joint efficiencies of dissimilar weld joint as performance of the dissimilar weld joints is dictated by weaker metal of the combination. The tensile strength efficiency, yield strength efficiency, and elongation efficiency of similar and dissimilar weld joints are presented in Figure 8. All the FSW joints displayed approximately similar tensile strength efficiencies (79-85.6\%) however, vast difference was observed in yield strength efficiencies (14.7-81.1\%) and elongation efficiencies (40.5-141.7\%). Tensile strength, yield strength and elongation efficiencies of dissimilar weld joints were $79 \%, 14.7 \%$ and $73.5 \%$, respectively. Similar trend of results were reported by other researchers $[6,16]$.

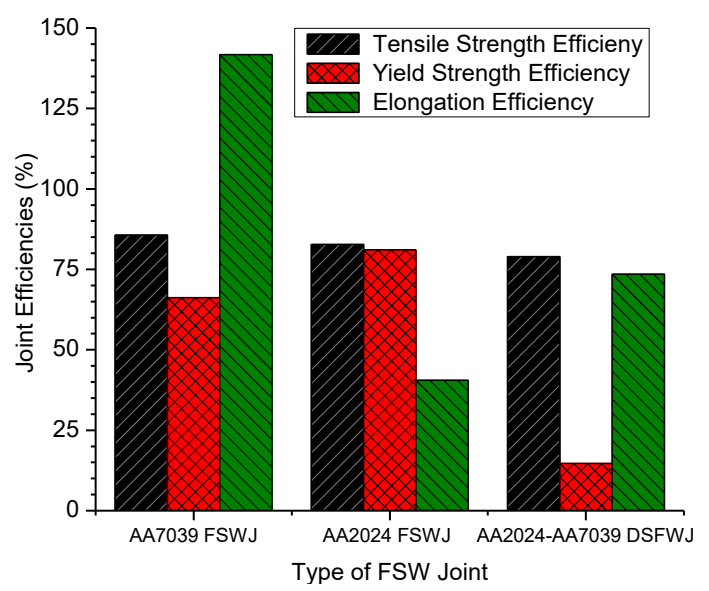

Figure 8. Comparison of different joint efficiencies of similar and dissimilar FSW joints.

Decrease in tensile strength of similar and dissimilar weld joints can be attributed to softening of peak hardened base metals. During FSW metallurgical bonding is achieved due to combined effect of extrusion and forging arising from extreme plastic deformation produced by rotating and traversing tool. The tool softens, flows and mixes both the metals in the stir zone for the formation of weld joint. Heat of welding promotes dissolution/coarsening of precipitates which is supposed to cause softening in weld joints. The mixing of base metals i.e. AA2024 and AA7039 alloys in stir zone is said to form mixture of both base metals. Composition of formed mixture i.e. weld metal in stir zone of dissimilar weld joints was $1.57 \% \mathrm{Mg}, 1.86 \% \mathrm{Cu}, 0.38 \% \mathrm{Mn}$, $2.51 \% \mathrm{Zn}, 93.61 \% \mathrm{Al}$. The weight $\%$ of $\mathrm{Cu}$ and $\mathrm{Zn}$ was found to be significantly lower than both the base metals which confirm the dissolution of strengthening precipitates. Therefore, dominance of dissolution over the reprecipitation leads to softening of weld joint and consequently, lower were the tensile properties of dissimilar and similar weld joints than base metals. Weld tensile properties could not be restored to the level of base metals as the extent of reprecipitation combined with strain hardening was not to optimum level. The 
sharp decrease in ductility of AA2024 similar weld joint and dissimilar weld joint may be attributed to the presence of coarsened precipitates and severe localized stress concentration in weak zone leading to premature failure and reduced $\%$ elongation of the welds. The reason for localized stress concentration and premature failure of weld joints may be due to great mismatch in strength of metals.

\subsection{Fractography}

Failure of weld joint occurred from the low strength weak zone during uniaxial tensile testing. Failure locations are indirect indication of weak zone of transverse weld joints which comprises all the zones i.e. WNZ, TMAZ, HAZ and base metal(s). The dissimilar weld joint failed from WNZ on RS i.e. AA2024 side while similar weld joint of AA7039 failed from HAZ on AS and that of AA2024 failed from WNZ/TMAZ interface on AS. The significant necking was observed at fractured end of base metal samples compared to similar and dissimilar FSW welds. However, similar FSW welds of AA7039 exhibited greater extent of necking as compared to other welds. Fractured surfaces after tensile testing were studied with SEM coupled with EDS to identify the mode of failure and type of strengthening particles in failure region. SEM fractographs for base metals and similar welds are presented in Figure 9. AA2024 base metal underwent ductile fracture as evident from fibrous fracture surface, covered with dimples. Few dimples of large size were also clearly visible on the fracture surfaces. Further, some relatively featureless flat regions with extremely tiny dimples were also observed (Figure 9 a). While, similar welds of AA2024 alloy exhibited brittle fracture mode as fracture surfaces of AA2024 similar welds showed few tiny dimples (Figure $9 \mathrm{c}$ ). This is in accordance to lower elongation efficiency of AA2024 similar weld joints. The AA7039 base metal and similar weld both displayed well defined equiaxed dimples (Figure $9 \mathrm{~b} \& \mathrm{~d}$ ). Inside the dimples, fractured $\eta$ precipitates were present (Figure $9 \mathrm{~b} \& \mathrm{~d}$ ). AA7039 similar weld showed merging tear ridges. All these features suggests ductile fracture mode to AA7039 base metal and similar weld joints. Fractographs for dissimilar weld joints along with EDS shows the presence of $\mathrm{Cu}$ rich particles in failure region (Figure 10). At low magnification the fracture surface appeared to be fibrous and had few tear ridges as evident from figure 10 a. At high magnification (Figure 10 b \& c) fracture surfaces were covered with deep and equiaxed dimples. Fractured particles and tear ridges were also seen at high magnification (Figure $10 \mathrm{c}$ ). The tear ridges separate a region, comprising a population of dimples from other region and are believed to occur due to void coalescence. Materials' ability to undergo plastic deformation is reflected by tear ridges that grow with the amount of plastic deformation.
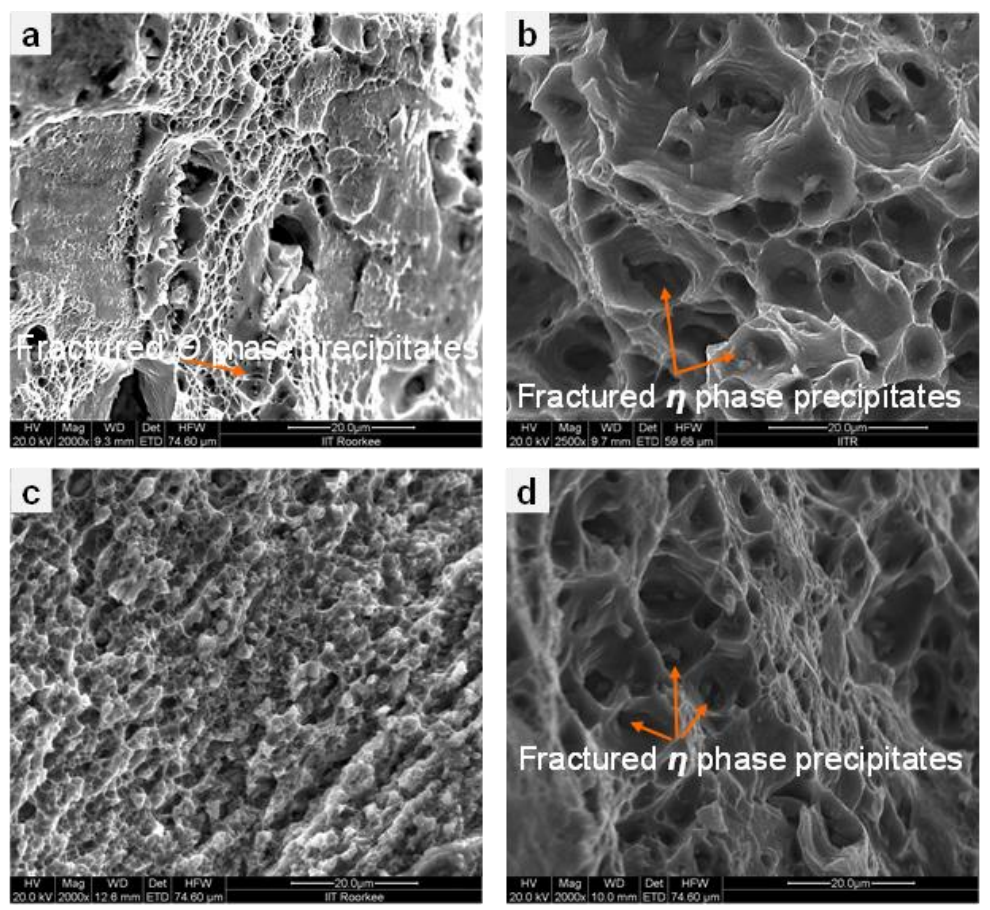

Figure 9. Fracture characteristics of (a) AA2024 base metal (b) AA7039 base metals, (c) AA2024 similar welds and, (d) AA7039 similar welds. 
The fracture surfaces of AA2024 base metal and that of similar weld were covered with $\theta\left(\mathrm{Al}_{2} \mathrm{Cu}\right)$ type precipitates while $\eta\left(\mathrm{ZnMg}_{2}\right)$ were found on the fracture surfaces of AA7039 base metal and its similar weld, as confirmed by EDS study. In case of dissimilar welds, $\eta$ and $\theta$ precipitates were found on fracture surfaces after tensile tests. However, percentage weight of $\mathrm{Zn}$ was considerably lower than $\mathrm{Cu}$, which is expected as failure occurred through a $\mathrm{Cu}$ rich region i.e. the WNZ toward RS (Figure $10 \mathrm{~d}$ ). The nucleation of the voids initiates when hard and brittle strengthening particles fracture to maintain compatibility of deformation. Subsequent growth of voids followed by coalescence resulted in the formation of cracks. These cracks propagate and ultimately lead to fracture as the remaining area of cross section was unable to support the applied load. High elongation efficiency of dissimilar welds and presence of dimples on fracture surface suggests ductile mode of fracture for dissimilar welds.
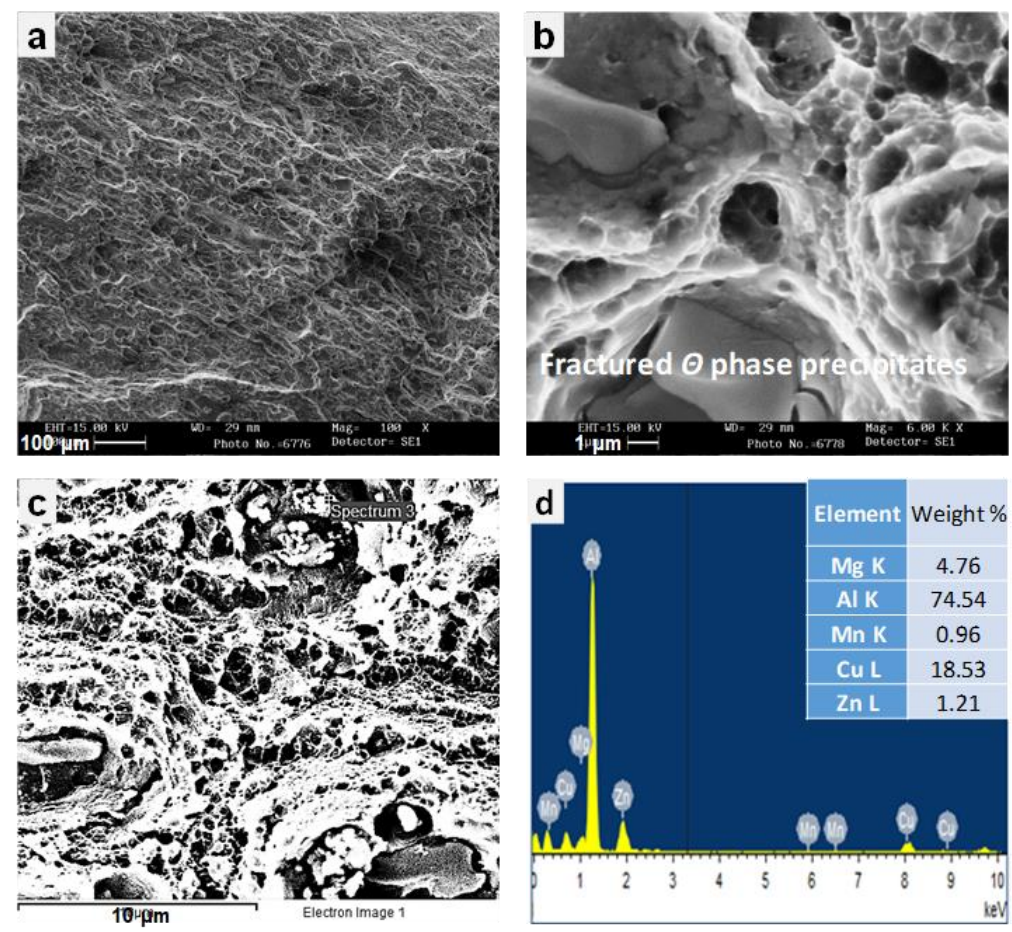

Figure 10. Fracture characteristics of dissimilar weld (a) 100X magnification fractograph (b) and (c) high magnification fractograph, and (d) EDS depicting Cu rich failure region.

\section{Conclusions}

Encouraging joint properties were obtained in similar as well as dissimilar joints of aluminum alloy AA2024 and AA7039. Developed joints displayed feature characteristics of FSW. Dissimilar weld joints presented heterogeneous lamellar microstructure comprising both the base metals. Mechanical mixing and insufficient diffusion were believed to be the reason for heterogeneous microstructure and increase in the weight $\%$ of $\mathrm{Zn}$ from RS to AS. The zones rich in either $\mathrm{Zn}$ or $\mathrm{Cu}$ were also observed in the stir zone of dissimilar joints. Microhardness profiles of similar joints were relatively uniform than dissimilar joints. Dissimilar joints presented higher average microhardness in WNZ and HAZs than similar joints suggesting the dominance of reprecipitation over dissolution/coarsening. Despite higher average microhardness dissimilar joints showed tensile properties lower than both the similar FSW joints. Compared to tensile strength vast difference was observed in yield strength and elongation at fracture of all the FSW joints. The fracture location and mode of fracture was found to be dependent on the type of FSW i.e. similar or dissimilar. Dissimilar joints and AA7039 similar joints exhibited ductile fracture mode while other similar joints showed brittle fracture mode.

\section{Acknowledgement}

The support provided by Science and Engineering Research Board, DST, GOI through Grant No. ECR/2016/001738 to carry out this research work is thankfully acknowledged. 


\section{References}

[1] Khan, N. Z., Siddiquee, A. N., Khan Z. A.: Friction Stir Welding Dissimilar Aluminum Alloys. CRC Press, Boca Raton, 2017.

[2] Cavaliere, P., Nobile, R., Panella, F. W., Squillace, A.: Mechanical and microstructural behaviour of 2024-7075 aluminium alloy sheets joined by friction stir welding, International Journal of Machine Tools and Manufacture, 46 (2006), 588-594.

[3] Mishra, R. S., Ma, Z. Y.: Friction stir welding and processing, Materials Science and Engineering: R: Reports, 50 (2005), 1-78.

[4] Sharma, C., Dwivedi, D. K., Kumar, P.: Effect of welding parameters on microstructure and mechanical properties of friction stir welded joints of AA7039 aluminum alloy, Materials \& Design 36 (2012), 379-390.

[5] Threadgill, P. L., Leonard, A., Shercliff, H. R., Withers, P. J.: Friction stir welding of aluminum alloys, International Materials Reviews, 54 (2009), 49-93.

[6] Khodir, S. A., Shibayanagi, T.: Friction stir welding of dissimilar AA2024 and AA7075 aluminum alloys, Materials Science and Engineering: B, 1-3 (2008), 82-87.

[7] Silva, A. A. MD., Arruti, E., Janeiro, G., Aldanondo, E., Alvarez, P., Echeverria, A.: Material flow and mechanical behaviour of dissimilar AA2024-T3 and AA7075-T6 aluminium alloys friction stir welds, Materials \& Design 32 (2011), 2021-2027.

[8] Ahmed, M. M. Z., Ataya, S., Seleman, M. M. E. S., Ammar, H. R., Ahmed, E., Friction stir welding of similar and dissimilar AA7075 and AA5083, Journal of Materials Processing Technology, 242 (2017), 77-91.

[9] Zhang, C., Huang, G., Cao, Y., Zhu, Y., Liu, Q.: On the microstructure and mechanical properties of similar and dissimilar AA7075 and AA2024 friction stir welding joints: Effect of rotational speed, Journal of Manufacturing Processes, 37 (2019), 470-487.

[10] Khalilabad, M. M., Zedan, Y., Texier, D., Jahazi, M., Bocher, P.: Effect of tool geometry and welding speed on mechanical properties of dissimilar AA2198-AA2024 FSWed joint, Journal of Manufacturing Processes Part A, 34 (2018), 86-95.

[11] Cavaliere, P., Panella, F.: Effect of tool position on the fatigue properties of dissimilar 2024-7075 sheets joined by friction stir welding, Journal of Materials Processing Technology, 206 (2008), 249255.

[12] Saravanan, V., Banerjee, N., Amuthakkannan, R., Rajakumar, S.: Microstructural evolution and mechanical properties of friction stir welded dissimilar AA2014-T6 and AA7075-T6 aluminium alloy joints, Metallography, Microstructure, and Analysis, 4 (2015), 178-87.

[13] Zadpoor, A. A., Sinke, J., Benedictus, R., Pieters, R.: Mechanical properties and microstructure of friction stir welded tailor-made blanks, Material Science and Engineering A, 494 (2008), 281-90.

[14] Avinash, P., Manikandan, M., Arivazhagan, N., Devendranath, R. K., Narayanan, S.: Friction stir welded butt joints of AA2024 T3 and AA7075 T6 aluminum alloys, Procedia Engineering 75 (2014), 98-102.

[15] Bahemmat, P., Haghpanahi, M., Givi, M. K. B., Seighalani, K. R.: Study on dissimilar friction stir butt welding of AA7075-O and AA2024-T4 considering the manufacturing limitation, International Journal of Advanced Manufacturing Technology, 59 (2012), 939-53.

[16] Venkateswarlu, D., Rao, P. N., Mahapatra, M. M., Harsha, S. P., Mandal, N. R.: Processing and optimization of dissimilar friction stir welding of AA 2219 and AA 7039 alloys, Journal of Materials Engineering and Performance, 24 (2015), 4809-24.

[17] Sharma, C., Upadhyay, V., Narwariya, B. S.: Tensile properties of dissimilar friction stir weld joints of Al-2024 and Al-7039 alloys, Materials Research Express, 6 (2019), 026524.

[18] Khan, N. Z., Siddiquee, A. N., Khan, Z. A., Mukhopadhyay, A. K.: Mechanical and microstructural behavior of friction stir welded similar and dissimilar sheets of AA2219 and AA7475 aluminum alloys, Journal of Alloys and Compounds, 695 (2017), 2902-8.

[19] Rhodes, C. G., Mahoney, M. W., Bingel, W. H., Spurling, R. A., Bampton, C. C.: Effects of friction stir welding on microstructure of 7075 aluminium, Scripta Materialia, 36 (1997), 69-75. 
[20] Sharma, C., Dwivedi, D. K., Kumar, P.: Influence of pre-weld temper conditions of base metal on microstructure and mechanical properties of friction stir weld joints of $\mathrm{Al}-\mathrm{Zn}-\mathrm{Mg}$ alloy AA7039, Materials Science \& Engineering A, 620 (2015), 107-119.

[21] Su, J. Q., Nelson, T. W., Mishra, R. S., Mahoney, M. W.: Microstructural investigation of friction stir welded 7050-T651 aluminium, Acta Materilia, 51 (2003) 713-729. 